\title{
Escrita Inventada e Aquisição da Leitura em Crianças de Idade Pré-escolar ${ }^{1}$
}

\author{
Margarida Alves Martins ${ }^{2}$ \\ Ana Albuquerque \\ Liliana Salvador \\ Cristina Silva \\ ISPA - Instituo Universitário de Ciências Psicológicas Sociais e da Vida
}

\begin{abstract}
RESUMO -Vários investigadores mostraram que actividades de escrita inventada com crianças em idade pré-escolar contribuem para a aquisição da literacia, tendo um impacto positivo na evolução da sua escrita e consciência fonológica. O nosso objectivo foi avaliar o impacto de um programa de escrita inventada na aquisição da leitura. Participaram 60 crianças Portuguesas de 5 anos que não sabiam ler nem escrever. Foram aleatoriamente divididas em dois grupos, experimental e controlo, equivalentes quanto às letras conhecidas, consciência fonológica e inteligência. O grupo experimental participou num programa de escrita inventada e o grupo de controlo num programa de leitura de histórias. A leitura de palavras foi avaliada num pré-teste, pós-teste e pós-teste postergado. O grupo experimental teve resultados superiores nos dois pós-testes.
\end{abstract}

Palavras-chave: programa de escrita, leitura, educação infantil

\section{Invented Spelling and Reading Acquisition in Pre-school-age Children}

\begin{abstract}
Several researchers have shown that invented spelling activities with pre-school-age children contribute to literacy acquisition, having a positive impact on the evolution of children's writing and phonological awareness. Our aim was to assess the impact of an invented spelling programme on reading acquisition. The participants were 60 Portuguese 5 -yearold children who were not able to read or write. Children were randomly divided in two groups, experimental and control, equivalent in terms of knowledge of letters, phonological abilities and intelligence. The experimental group participated in an invented spelling programme and the control group in a story reading programme. Children's word reading was evaluated in a pre-test, a post-test and a differed post- test. Experimental group had better results in both post-tests.
\end{abstract}

Keywords: spelling programme, reading, pre-school

$\mathrm{Na}$ sociedade actual, o interesse pela linguagem escrita surge, frequentemente, antes do ensino formal da leitura e da escrita. Desde cedo, as crianças interagem com a escrita e com aqueles que a dominam e utilizam na vida quotidiana e vão assim desenvolvendo uma motivação para a explorar. $\mathrm{O}$ interesse pela escrita manifesta-se através da curiosidade pelas letras e sons e pela produção de escritas inventadas, que fornecem, de acordo com vários investigadores, um importante contributo para a aquisição da literacia (Adams, 1998; Mann, 1993; McBride-Chang, 1998; Ouellette \& Sénéchal, 2008a, 2008b; Tolchinsky, 2005; Treiman, 1998).

Read (1971), a par de Chomsky (1970) e Clay (1972), foi dos primeiros autores a atribuir significado linguístico à escrita inventada que pode ser definida como a tentativa de fonetizar, antes de qualquer aprendizagem formal, os sons das palavras à medida que se procura escrevê-las. Não se trata de um processo de memorização e de restituição de escritas convencionais, mas sim de um processo de experimentação por parte das crianças que, apesar de não saberem ler, usam os conhecimentos que adquiriram sobre as correspondências

1 Apoio: Fundação para a Ciência e a Tecnologia (FCT) Projecto: PTDC/PSI-EDD/110262/2009

2 Endereço para correspondência: Instituto Universitário de Ciências Psicológicas Sociais e da Vida - ISPA, Rua Jardim do Tabaco, 34, Lisboa, Portugal. CEP: 1149-041. E-mail: mmartins@ispa.pt letras-sons e procuram representar na escrita os sons que identificam o mais fielmente possível, pelo que, conclui o autor, a maioria dos erros que as crianças cometem são sistemáticos mas reveladores da consciência fonética já emergente.

As tentativas de escrita das crianças, antes do início do ensino formal, revelam que a noção de que as letras representam os fonemas da linguagem oral é precedida por concepções pré-alfabéticas da linguagem escrita. Autores como Ferreiro (1988) e Ferreiro e Teberosky (1979) demonstraram que as crianças evoluem nas suas hipóteses sobre o funcionamento do código escrito, progredindo de concepções em que a escrita não é determinada por critérios linguísticos até concepções alfabéticas da escrita. Também Ehri (1991), nos estudos que desenvolveu sobre a evolução da escrita, identificou uma primeira fase a que chamou préalfabética, na qual as crianças combinam arbitrariamente letras e pseudo-letras na sua escrita, sem ter em atenção as relações entre as letras e os sons do oral.

Se é hoje consensual que a escrita inventada constitui uma actividade que leva à descoberta do princípio alfabético, permitindo a compreensão da relação entre a oralidade e a escrita, é menos evidente o seu impacto na leitura, devendo por isso esta dimensão ser objecto de investigações mais aprofundadas.

Diversos autores (e.g. Alves Martins \& Silva, 2006a, 2006b; Ouellette \& Sénéchal, 2008a; Silva \& Alves Martins, 
2002; Treiman, 1998, 2004) consideram que as actividades de escrita inventada são um instrumento importante de ajuda à compreensão do princípio alfabético, na medida em que, quando tentam escrever, as crianças são levadas a pensar na linguagem oral e nos sons que a constituem, na linguagem escrita, e nas letras que a compõem e nas relações entre ambas. Com efeito, tem sido demonstrado que as actividades de escrita inventada desenvolvidas com crianças em idade pré-escolar promovem o desenvolvimento da consciência fonológica e, em particular, da consciência fonémica e levam a progressos nas escritas das crianças (Alves Martins \& Silva, 2006 a, 2006b; Silva \& Alves Martins, 2002). Segundo Ouellette e Sénéchal (2008a) as escritas inventadas constituem uma janela para as competências cognitivas e linguísticas implicadas nas aquisições precoces de literacia.

Por seu turno, os conhecimentos adquiridos informalmente sobre o nome das letras ajudam as crianças a detectar os nomes das letras na pronúncia de algumas palavras (Treiman, 2004), reflectindo-se nos processos de fonetização, ou seja, na forma como as crianças são capazes de mobilizar as letras corretas na representação dos sons que identificam na linguagem oral. Esse processo favorecerá a compreensão da lógica alfabética, na medida em que as próprias letras servem de suporte para uma análise mais sistemática da sequência de sons nas palavras. Por outro lado, as propriedades articulatórias dos fonemas que integram as palavras a escrever poderão influenciar a qualidade das escritas infantis, já que alguns fonemas serão mais fáceis de isolar no fluxo do discurso do que outros. De acordo com Liberman, Shankweiler, Fischer e Carter (1974), as crianças tomam mais facilmente consciência das vogais do que das consoantes e identificam mais facilmente consoantes fricativas do que oclusivas. Cardoso-Martins e Batista (2005) mostraram também que as letras nas escritas silábicas das crianças correspondiam, em geral, às vogais ou então às consoantes cujo nome podia ser detectado na pronúncia da palavra.

Se o impacto de actividades de escrita inventada no desenvolvimento da escrita de crianças em idade pré-escolar e em particular no aparecimento de escritas fonetizadas está bem fundamentado na literatura, são ainda reduzidos os estudos que analisam o seu impacto no desenvolvimento da leitura (Caravolas, Hulme, \& Snowling, 2001). Ainda assim, os trabalhos de natureza experimental e correlacional existentes sugerem uma relação entre as escritas inventadas e a aquisição precoce da leitura (Mann, 1993; McBride-Chang, 1998; Richgels, 1995; Shatil, Share, \& Levin, 2000).

Um dos primeiros estudos experimentais nesta área é o de Ehri e Wilce (1987), o qual demonstrou que crianças de idade pré-escolar treinadas a escrever foneticamente palavras simples aprendem a ler palavras semelhantes em poucos ensaios melhor do que as crianças do grupo de controlo. No entanto, é de assinalar que neste estudo o treino não foi adaptado ao nível de desenvolvimento de cada criança e não envolveu tentativas de escrita espontânea. Por outro lado, o grupo experimental pode ter conseguido ler palavras simples por estar mais familiarizado com estímulos semelhantes, dado ter sido exposto a esse tipo de estímulos durante o programa de treino.

Num estudo naturalístico, Clarke (1988) comparou dois programas desenvolvidos em duas turmas de $1^{\circ}$ ano, um que incluía escrita inventada e outro, ensino de escrita convencional. A turma em que a escrita inventada foi desenvolvida apresentou resultados superiores na descodificação de palavras e no reconhecimento de palavras irregulares. Esse estudo, que mostrou a importância da escrita inventada na leitura, teve no entanto algumas falhas no controlo de variáveis, como a consciência fonológica que não foi inicialmente avaliada e que pode ter influenciado os resultados.

Rieben, Ntamakiliro, Gonthier e Fayol (2005) efectuaram um estudo com três grupos de crianças de língua francesa de 5 anos. Nesse estudo foi contrastado o efeito do treino de escritas inventadas, treino de escritas inventadas com feedback corretivo e cópia de palavras. O grupo que treinou as escritas inventadas com feedback corretivo apresentou mais progressos na leitura das palavras praticadas. No entanto, não foram encontradas diferenças entre os três grupos na leitura de palavras novas, nos progressos das escritas inventadas nem em medidas de consciência fonológica.

Vários factores poderão explicar o impacto limitado desse programa de intervenção. Em primeiro lugar, provavelmente, os sujeitos experimentais eram crianças cujo nível inicial de escrita inventada não era muito elevado, uma vez que conheciam um número reduzido de letras. Por outro lado, não parece ter havido um processo de intervenção explícito na medida em que os procedimentos ao longo das 18 sessões centravam-se apenas no incentivo da escrita com soletração das palavras (nunca se estimulando a reflexão sobre o modo de escrever). Finalmente, o teste de leitura usado no pós-teste era relativamente complexo.

Um outro estudo de Ouellette e Sénéchal (2008b) com crianças de língua inglesa, procurou igualmente avaliar se as escritas inventadas poderiam desempenhar um papel causal na aprendizagem da leitura. Três grupos de crianças participaram num programa de intervenção de quatro semanas. As crianças do grupo de escritas inventadas foram convidadas a escrever palavras, da melhor maneira que eram capazes e recebiam um feedback corretivo, sendo-lhes apresentada uma produção escrita com mais uma letra correta do que aquela que tinham conseguido produzir. As crianças dos dois grupos de comparação foram treinadas respectivamente em competências fonológicas e em desenhos. As crianças do grupo de intervenção em escritas inventadas apresentaram um melhor desempenho na consciência fonológica, na consciência ortográfica e na leitura de palavras usadas na intervenção. Por outro lado, esse grupo aprendeu mais facilmente a ler palavras numa tarefa de aprendizagem de leitura de palavras do que as crianças dos outros dois grupos. Esses resultados, ao contrário do estudo anterior, apontam para a ideia de que as escritas inventadas facilitam a integração de conhecimentos fonológicos e ortográficos, favorecendo assim a aquisição da leitura.

As diferenças encontradas nos dois últimos estudos referenciados, bem como a ausência de estudos em que a evolução das escritas inventadas e o seu impacto na leitura sejam decorrentes de programas de treino em que as crianças são objectivamente colocadas num processo activo que implique reflexão sobre a forma de escrever, são factores que nos influenciaram a procurar perceber o impacto de programas de intervenção de escrita inventada na leitura, 
em crianças de língua portuguesa. A pertinência de um estudo dessa natureza acentua-se quando existe claramente uma lacuna na literatura sobre as relações entre a escrita e a leitura em crianças antes do início do ensino formal da leitura e da escrita.

Essa questão tem no entanto de ser equacionada no quadro das diferenças entre línguas. Os sistemas de escrita alfabética combinam princípios fonográficos - codificação de unidades fonéticas através de um número limitado de letras - e semiográficos - notação de unidades significativas - num quadro complexo de correspondências entre a dimensão oral/ escrita, na medida em que não existe uma relação biunívoca nem entre letras e fonemas, nem entre unidades gráficas com sentido (palavras) e morfemas (Blanche-Beneviste, 2002). A forma como os sistemas ortográficos combinam esses dois princípios introduz variações na opacidade dos sistemas de escrita. Assim, alguns sistemas ortográficos como o Servo-Croata ou o Finlandês são avaliados como sistemas transparentes por assentaram em correspondências grafo-fonéticas regulares, enquanto noutros como o Inglês ou o Francês, factores como a etimologia e a morfologia têm maior impacto na representação ortográfica das palavras. Deste ponto de vista, o sistema ortográfico Português é considerado sensivelmente mais opaco do que, por exemplo, o Italiano ou o Espanhol, mas claramente mais transparente do que o Inglês e o Francês. Considera-se, habitualmente, que a aprendizagem da leitura e da escrita nas línguas com sistemas de escrita transparentes se processa de modo mais fácil do que nas línguas com sistemas de escrita opacos (Goswami, Ziegler, Dalton, \& Schneider, 2003).

O principal objectivo deste estudo consiste, assim, em analisar o impacto de um programa de intervenção de escrita inventada na aquisição precoce da leitura num sistema de escrita relativamente transparente como o Português, em crianças a frequentar a educação infantil.

Formulou-se a seguinte hipótese: Os desempenhos em leitura (número de palavras corretamente lidas e número de grafemas corretamente descodificados), em situação de pósteste e de pós-teste postergado são superiores nas crianças sujeitas ao programa de intervenção de escrita inventada em comparação com as crianças de um grupo de controlo.

\section{Método}

\section{Delineamento Experimental}

Trata-se de um estudo experimental em que foram constituídos dois grupos, um experimental e um de controlo. O grupo experimental foi sujeito a um programa de escrita inventada enquanto o grupo de controlo participou em actividades de leitura de histórias. Foram realizados um pré-teste, um pós-teste e um pós-teste postergado de leitura.

\section{Participantes}

Participaram neste estudo 60 crianças, 28 do sexo feminino e 32 do sexo masculino, com idade média de 5 anos e 5 meses a frequentar quatro jardins-de-infância, três da rede privada e um da rede pública da região de Lisboa, Portugal. Quer o pai, quer a mãe dessas crianças tinham em média 14 anos de escolaridade, sendo que a escolaridade do pai ia dos quatro aos 18 anos e a da mãe dos nove aos 18 anos.

Nenhuma das actividades desses jardins-de-infância incluía a escrita inventada, assim como nenhuma das crianças sabia ler ou produzia escritas alfabéticas, condição essencial para a sua participação. Outra condição para a participação das crianças era o seu conhecimento das vogais (A, E, I, O, $\mathrm{U})$ e das consoantes B, D, F, P, T, V, dado que essas eram as letras que compunham as palavras do pré e do pós-teste.

As crianças de cada jardim-de-infância foram aleatoriamente distribuídas por dois grupos, experimental e de controlo, que ficaram constituídos por 30 crianças cada.

\section{Instrumentos}

\section{Seleção dos participantes - Avaliação da escrita inventada.}

Pediu-se às crianças que escrevessem, o melhor que conseguissem, seis palavras que lhes foram ditadas. As palavras eram comuns para crianças desta idade e consistiam em monossílabos e dissílabos de estrutura simples (bola, pai, tia, dedo, fato, vida).

A escrita das crianças foi classificada em alfabética (sempre que fossem realizadas correspondências grafofonéticas corretas e adequada codificação da estrutura fonética com a possibilidade de ocorrência de erros ortográficos) e não alfabética (quando, podendo existir já tentativas de fonetização correta das palavras, a escrita não era alfabética convencional). Foram selecionadas as crianças cuja escrita era não alfabética.

\section{Seleção dos participantes - Avaliação da leitura.}

Foram apresentados vários cartões com palavras escritas em letras maiúsculas e perguntou-se às crianças: "O que é que achas que está aqui escrito?" As palavras utilizadas foram as mesmas usadas na avaliação da escrita inventada para efeitos de selecção inicial dos participantes. Procedeu-se ao registo das palavras lidas pelas crianças, tendo sido excluídas aquelas que leram qualquer uma das palavras apresentadas.

\section{Seleção dos participantes - Avaliação do conhecimento das letras.}

Para avaliar o conhecimento das letras foi utilizada uma prova constituída por 26 cartões em que estavam impressas, em maiúsculas e minúsculas, cada uma das letras do alfabeto. As crianças deviam responder às seguintes perguntas: Conheces esta letra? Como se chama? Sabes que som faz esta letra? Os cartões foram apresentados numa ordem fixa determinada aleatoriamente. Cada letra conhecida (nome e som) foi cotada com um ponto, sendo a cotação máxima de 26 pontos. Essa prova foi adaptada a partir da prova de conhecimento das letras de Silva e Alves Martins (2002). Só foram selecionadas as crianças que conheciam pelo menos as cinco vogais e as seis consoantes $(\mathrm{B}, \mathrm{D}, \mathrm{F}, \mathrm{P}, \mathrm{T}, \mathrm{V})$ presentes nas palavras a serem utilizadas neste estudo. 
Avaliação da consciência fonológica.

Para controlo da equivalência entre o grupo experimental e o de controlo, foi avaliada a consciência fonológica. Foram utilizadas duas provas da bateria de provas fonológicas de Silva (2008), a prova de classificação da sílaba inicial e a prova de classificação do fonema inicial. Ambas as provas eram compostas por 14 itens cada, precedidos de dois exemplos. Cada item era composto por quatro imagens que representavam quatro palavras, sendo que duas dessas palavras começavam pela mesma sílaba (e.g., uva/asa/ unha/ilha) ou pelo mesmo fonema (e.g., alce/urso/arca/ovo) sendo pedido às crianças que as identificassem consoante o tipo de classificação requerida, silábica ou fonémica. Cada resposta correta foi cotada com um ponto. O número de pontos possíveis variava entre 0 e 14 pontos para cada uma das provas.

\section{Avaliação da inteligência.}

Para controlo da equivalência entre o grupo experimental e o de controlo, foi avaliada a inteligência das crianças com recurso às Matrizes Progressivas Coloridas de Raven (Raven, Raven, \& Court, 1998), sendo atribuído um ponto por cada resposta correta para uma pontuação máxima de 36 pontos.

\section{Avaliação da leitura no pré-teste, pós-teste e pós-teste postergado.}

Foram apresentadas às crianças 20 palavras mono e dissilábicas constituídas pelas 11 letras, com base nas quais as crianças foram seleccionadas. Das 20 palavras, 12 continham consoantes trabalhadas no decorrer do programa de intervenção, as oclusivas B, D, P, T (Baba, Bata, Bota, Dado, Dai, Dita, Pai, Pato, Pia, Tapa, Tio, Ti) e seis continham consoantes não trabalhadas, as fricativas F e V (Fada, Fio, Fita, Vai, Vi, Vota). A utilização de letras não trabalhadas teve como objectivo verificar a existência de processos de generalização. Cada uma das consoantes referidas iniciava três das palavras apresentadas, correspondendo assim as seis consoantes a 18 palavras. Também foram usadas duas palavras cuja letra inicial era uma vogal, $\mathrm{A}$ e $\mathrm{O}$, à qual se seguia uma oclusiva e uma fricativa, respectivamente (Ato e Ova). As vogais que compunham as palavras utilizadas no pré e pós-testes foram A, I, O, com diversos valores fonémicos: $[\mathrm{a}],[\alpha][\mathrm{i}],[\mathrm{o}] \mathrm{e}[\mathrm{u}]$. As vogais usadas imediatamente a seguir à consoante ou no início da palavra eram vogais abertas (e.g., ato [atu]; bota [bot $\alpha$ ). Foram apresentados 20 cartões com as palavras em questão e foi pedido às crianças que as lessem. A ordem das palavras foi escolhida aleatoriamente e foi a mesma para todas as crianças. Procedeu-se ao registo escrito e simultaneamente à gravação das palavras lidas para uma análise posterior. Utilizaram-se dois "scores": o número de palavras corretamente lidas e o número de grafemas corretamente descodificados. Apresentam-se seguidamente exemplos de leitura das palavras e de codificação das mesmas. Na leitura da palavra "Dado" o João leu "Boca" tendo-lhe sido atribuídos 0 pontos. Na leitura da palavra
"Fita" a Leonor leu "Flor", tendo-lhe sido atribuído 1 ponto. $\mathrm{Na}$ leitura da palavra "Vai" a Marina leu "Vá" tendo-lhe sido atribuídos 2 pontos. Na leitura da palavra "Bota" o Joaquim leu "Boto" tendo-lhe sido atribuídos 3 pontos. Para a leitura correta da palavra "Fada" foram atribuídos 4 pontos à Sara. Procedeu-se à contagem dos grafemas corretamente descodificados em cada uma das palavras. A descodificação dos grafemas só foi considerada correta quando respeitava a ordem pela qual eles apareciam na palavra-alvo. Assim, por exemplo, quando a Ana leu a palavra "Pia" como "Pai" só foi cotado 1 ponto correspondente à descodificação correta da letra P. A cotação variou entre 0 e 67 pontos.

Procedeu-se também à cotação das palavras lidas corretamente na sua totalidade, sendo atribuído 1 ponto a cada palavra em que a leitura foi bem sucedida com uma cotação máxima de 20 pontos.

Essa classificação foi realizada por dois avaliadores independentes que não sabiam a que grupo pertencia cada criança, tendo a acordo inter-avaliadores, usando a estatística Kapa de Cohen, sido de 0,97 para o pré-teste e de 0,96 para o pós-teste e para o pós-teste postergado.

\section{Programa de intervenção de escrita inventada.}

O programa foi desenvolvido com cada criança, individualmente, tendo a duração de 10 sessões de 15 minutos cada, com uma frequência de duas sessões por semana.

No decurso de cada sessão era pedido à criança que escrevesse, como soubesse e sem qualquer ajuda, um conjunto de palavras que lhe iam sendo ditadas. Após a escrita de cada palavra, era-lhe perguntado se queria ver como é que outro menino tinha escrito essa mesma palavra e era-lhe mostrado um cartão com uma escrita alfabética, não sendo dito que se tratava da escrita correta. Era em seguida pedido à criança que comparasse as duas escritas, escolhesse qual das duas versões melhor representaria a palavra e justificasse as razões dessa escolha. Nesse processo de comparação, a criança devia começar por olhar para a $1^{\mathrm{a}}$ letra, depois para a $2^{\mathrm{a}}$, e assim sucessivamente. $\mathrm{O}$ adulto ajudava-a, levando-a a pensar nos sons que melhor corresponderiam a cada letra. As ajudas eram adaptadas a cada criança.

Foram utilizadas seis palavras por sessão, compostas pelas oclusivas P, B, T, D e pelas vogais, tendo-se recorrido nas primeiras quatro sessões ao uso de algumas palavras facilitadoras (Mann, 1993), isto é, palavras em que a sílaba inicial coincide com o nome da primeira letra (por exemplo, "Peta" em que a sílaba inicial "pe" corresponde ao nome da letra P de forma a facilitar a descoberta dessa letra.

A utilização de consoantes oclusivas está relacionada com o facto de serem mais difíceis de isolar do que as fricativas e supõe que, uma vez adquirida essa capacidade em relação às oclusivas, maior facilidade haverá na generalização do procedimento para as fricativas. Todas as vogais utilizadas em primeira ou segunda posição consistiam em vogais abertas, de modo a que o isolamento fonémico fosse mais fácil. As palavras possuíam uma estrutura simples, sendo a maioria dissílabos de estrutura CVCV, alguns de estrutura VCV, e monossílabos de estrutura CVV e CV. 
Apresenta-se seguidamente um exemplo ilustrativo das interacções ocorridas durante o programa.

Margarida

Exp.: Margarida, vou pedir-te que escrevas, como souberes, como achares que é, umas palavras, pode ser? Então quero que escrevas a palavra BATO.

Margarida: BATO? Está bem (escreve ABE).

Exp.: Queres ver como é que uma menina que também tem 5 anos como tu escreveu?

Margarida: Sim.

Exp. Mostra BATO escrito corretamente.

Exp.: Olha lá, que letras é que ela pôs?

Margarida.: $B, A, T, O$.

Exp.: E tu, que letras puseste?

Margarida: $A, B, E$.

Exp.: Então está diferente ou igual à da outra menina?

Margarida: Está diferente.

Exp.: Tu começaste por que letra?

Margarida: $A$.

Exp.: E a menina?

Margarida: Por B. Mas é por A.

Exp.: Qual era a palavra que tinhas de escrever?

Margarida: BA-TO (e salienta o A). Por isso é que é com A.

Exp.: Então porque será que a menina pôs $B$ ?

Margarida: BA-TO, BA, BA, tem outro som. Não é só o A.

Exp.: Então e que som será esse?

Margarida: B, B, Bruno, é B. A menina tem razão, é $B$.

\section{Programa do grupo de controlo}

O programa do grupo de controlo consistiu em actividades de leitura de histórias. As crianças ouviam ler uma história em cada sessão. O número e duração das sessões foram idênticos ao do programa de intervenção de escrita inventada.

\section{Procedimentos}

A avaliação das crianças e os programas do grupo experimental e do grupo de controlo desenrolaram-se numa sala dentro da escola e foram conduzidos por dois psicólogos da educação com experiência na avaliação de crianças dessa faixa etária.

A avaliação inicial foi efectuada durante os meses de novembro e dezembro, após a autorização das escolas e o consentimento informado dos pais e decorreu em duas sessões com uma semana de intervalo.
O pré-teste foi realizado em janeiro. Os programas iniciaram-se uma semana após a realização do pré-teste. Uma semana após o término do programa foi realizado o pós-teste. O pós-teste postergado foi realizado quatro meses após o pós-teste.

\section{Programa de escrita inventada}

$\mathrm{Na} 1^{\mathrm{a}}$ sessão, após a escrita de duas palavras facilitadoras "Peta" e "Pera", foi pedido às crianças que escrevessem outras palavras começadas pela letra P, seguida de diversas vogais, por exemplo, Papa, Pio, Podo. Quando a criança comparava a sua escrita das palavras facilitadoras com a escrita alfabética que lhe era apresentada, o adulto chamavalhe unicamente a atenção para a $1^{\mathrm{a}}$ letra. Nas outras palavras, após a criança ter conseguido escrever corretamente a $1^{\mathrm{a}}$ letra, era chamada a atenção para a $2^{\mathrm{a}}$ e depois para as restantes letras, à medida que a criança ia sendo capaz de as escrever alfabeticamente.

$\mathrm{Na} 2^{\mathrm{a}}$ sessão foi utilizado o mesmo procedimento, mas as palavras começavam todas pela letra T (Ex. Teta, Ter, Tato, Tipo, Topa), na $3^{\text {a }}$ sessão pela letra B (Ex. Bebo, Beba, Bato, Bibe, Boto) e na $4^{\text {a }}$ pela letra D (ex. Dedo, Dele, Data, Dito, Dobo). A partir da $5^{\text {a }}$ sessão as palavras começavam por diversas letras (Ex. Pipo, Ata, Bia, Dota).

\section{Resultados}

Começamos por analisar a equivalência entre o grupo experimental e o de controlo no que se refere à idade, nível de consciência fonológica (silábica e fonémica), total de letras conhecidas e inteligência, variáveis que poderiam ter impacto nos resultados obtidos. Apresentam-se na Tabela 1 as médias e desvios-padrão relativos a essas variáveis, para os dois grupos.

Foram realizados testes $t$ para amostras independentes, tendo como variável independente o grupo e como variáveis dependentes a idade, os resultados numa prova de consciência silábica, numa prova de consciência fonémica, o número de letras conhecidas e a inteligência, tendo sido obtidos os seguintes resultados: para a idade, $t(58)=0,23, p=0,823$; para a consciência silábica, $t(58)=-0,52, p=0,607$; para a consciência fonémica, $t(58)=-0,95, p=0,345$; para as letras conhecidas, $t(58)=-0,66, p=0,514$; para a inteligência, $t(58)=0,22, p=0,825$. Não se verificaram diferenças estatisticamente significativas entre os dois grupos.

Tabela 1.Caracterização dos grupos no que diz respeito à idade, inteligência, letras conhecidas, níveis de consciência silábica e fonémica

\begin{tabular}{lcccccccccc}
\hline & \multicolumn{2}{c}{ Idade } & \multicolumn{2}{c}{ Inteligência } & \multicolumn{2}{c}{ Letras } & \multicolumn{2}{c}{ Sílaba } & \multicolumn{2}{c}{ Fonema } \\
\cline { 2 - 11 } & $M$ & $D P$ & $M$ & $D P$ & $M$ & $D P$ & $M$ & $D P$ & $M$ & $D P$ \\
\hline G.E. & 66,27 & 3,57 & 17,00 & 2,64 & 17,69 & 3,51 & 6,21 & 3,65 & 4,36 & 2,03 \\
G.C. & 66,24 & 4,42 & 16,94 & 4,16 & 16,45 & 3,57 & 5,52 & 3,35 & 3,58 & 1,76 \\
\hline
\end{tabular}

Nota. G.E. $=$ Grupo experimental; G.C. $=$ Grupo de controlo 
No que se refere aos resultados na leitura de palavras, apresentam-se na Tabela 2 as medianas e as amplitudes dos dois grupos no pré-teste, pós-teste e pós-teste postergado.

Dada a não existência de distribuição normal das variáveis nem de homogeneidade de variâncias entre os grupos, realizamos dois testes de Mann-Witney, tendo como variável independente o grupo e como variável dependente o número de palavras corretamente lidas em situação de pós-teste ou de pós-teste postergado, tendo obtido os valores $U=208,0, p<.001$ e $r=.51$, para o pós-teste e $U=185,0$, $p<.001$ e $r=.54$ para o pós-teste postergado. Existem diferenças estatisticamente significativas entre os grupos nas duas situações, o que nos permite confirmar o impacto do programa de escrita inventada nos resultados em leitura das crianças.

Apresentam-se na Tabela 3, vários exemplos de leitura das palavras Dado, Fita, Bata e Vota por crianças do grupo experimental e do grupo de controlo nos três momentos de avaliação.

Tal como se pode verificar a partir dos exemplos apresentados na Tabela 3, as crianças de ambos os grupos, quando lhes é pedido, no momento do pré-teste, que leiam uma palavra, tentam adivinhar de que palavra se trata sem

Tabela 2. Medianas e amplitudes do número de palavras corretamente lidas no pré-teste, no pós-teste e no pós-teste

\begin{tabular}{ccccccc}
\hline & \multicolumn{2}{c}{ Pré } & \multicolumn{2}{c}{ Pós } & \multicolumn{2}{c}{ Postergado } \\
\cline { 2 - 7 } & $M d$ & $A T$ & $M d$ & $A T$ & $M d$ & $A T$ \\
\cline { 2 - 7 } G.E. & 0,00 & 0,00 & 2,00 & 14,00 & 2,00 & 17,00 \\
G.C. & 0,00 & 0,00 & 0,00 & 4,00 & 0,00 & 9,00 \\
\hline
\end{tabular}

Nota. G.E. $=$ Grupo experimental; G.C. $=$ Grupo de controlo

ter em conta as suas características ou tendo unicamente em conta a primeira letra. Já no pós-teste, enquanto as crianças do grupo de controlo mantêm os procedimentos anteriormente descritos, as do grupo experimental tentam descodificar as palavras apresentadas, chegando por vezes à sua leitura correta ou produzindo uma pseudo-palavra por não terem conseguido descodificar corretamente todos os grafemas. Esses procedimentos mantêm-se no pós-teste postergado.

Apresentam-se na Tabela 4, as medianas e as amplitudes do número de grafemas corretamente descodificados no préteste, pós-teste e pós-teste postergado de leitura pelas crianças do grupo experimental e do grupo de controlo.

Dado que não havia distribuição normal das variáveis nem homogeneidade de variância entre os grupos, foram realizados três testes de Mann-Witney, tendo o grupo como variável independente e o número de grafemas corretamente
Tabela 4. Medianas e amplitudes do número global de grafemas corretamente descodificados no pré-teste, no pós-teste e no pósteste postergado

\begin{tabular}{lllllll}
\hline & \multicolumn{2}{c}{ Pré } & \multicolumn{2}{c}{ Pós } & \multicolumn{2}{c}{ Postergado } \\
\cline { 2 - 7 } & $M d$ & $A T$ & $M d$ & $A T$ & $M d$ & $A T$ \\
\cline { 2 - 7 } G.E. & 6,00 & 23,00 & 27,00 & 62,00 & 24,00 & 67,00 \\
G.C. & 5,50 & 21,00 & 5,00 & 28,00 & 4,00 & 53,00 \\
\hline
\end{tabular}

Nota. G.E.= Grupo experimental; G.C. = Grupo de controlo

descodificados em cada um dos três momentos de avaliação como variável dependente. Assim, se no pré-teste de leitura os grupos se equivaliam, $U=448,0, p=.976$, no pós-teste as diferenças entre os grupos são significativas, $U=94,50$, $p<.001, r=.68$, diferenças essas que continuam a ser significativas no pós-teste postergado, $U=133,0, p<.001$, $r=.61$.

Para verificar a existência de processos de generalização de grafemas trabalhados durante o programa (B, D, P e T) para grafemas não trabalhados ( $\mathrm{F} \mathrm{e} \mathrm{V})$, calculamos a média do número de grafemas em posição inicial corretamente descodificadas nas duas condições (trabalhados e não trabalhados) relativas aos participantes do grupo experimental na situação de pós-teste e de pós-teste postergado. As medianas e as amplitudes são de $M d=0,83, A T=1,00$ para os grafemas trabalhados e não trabalhados nos dois pós-testes. Realizamos dois testes de Wilcoxon, um para os resultados obtidos no pós-teste, outro para os resultados obtidos no pósteste postergado, tendo verificado que não havia diferenças estatisticamente significativas entre as duas condições nem na situação de pós-teste, $T=-0,63, p=.531$, nem na situação de pós-teste postergado, $T=-0,86, p=.391$.

Podemos assim concluir que houve generalização dos procedimentos de fonetização da escrita para a leitura e de letras trabalhadas para letras não trabalhadas, quer em situação de pós-teste, quer em situação de pós-teste postergado.

\section{Discussão}

A hipótese formulada inicialmente de que os desempenhos em leitura em situação de pós-teste e de pós-teste postergado são superiores nas crianças sujeitas ao programa de intervenção de escrita inventada em comparação com as crianças de um grupo de controlo foi confirmada, na medida em que, tanto o número de palavras corretamente lidas, como o número de grafemas corretamente descodificados, em

Tabela 3. Exemplos de leitura de crianças do grupo experimental e do grupo de controlo no préteste, no pós-teste e no pós-teste postergado

\begin{tabular}{|c|c|c|c|c|c|c|}
\hline \multirow{2}{*}{ Palavra } & \multicolumn{3}{|c|}{ Grupo Experimental } & \multicolumn{3}{|c|}{ Grupo de Controlo } \\
\hline & Pré & Pós & Postergado & Pré & Pós & Postergado \\
\hline DADO & Ticá & Dato & Dado & Lápis & Porta & Tambor \\
\hline FITA & António & Ifa & Fitá & Francisco & Tomás & Quero \\
\hline BATA & Pio & Bato & Bata & Foca & Joana & Coelho \\
\hline VOTA & Dinis & Voto & Votuá & Botão & Caneta & Veado \\
\hline
\end{tabular}


situação de pós-teste e de pós-teste postergado, foi superior nas crianças sujeitas ao programa de intervenção de escrita inventada. Esses resultados suportam a ideia de que existe uma relação causal entre os progressos na escrita inventada e os processos de leitura, na linha do que é defendido por Richgels, (1995) e Ouellette e Sénéchal, (2008b).

De facto, o grupo experimental revelou-se capaz de transferir as competências adquiridas no programa de treino de escritas inventadas para a leitura de palavras. Essas competências mantêm-se ao longo do tempo pois, passados quatro meses do final do programa, as crianças do grupo experimental continuam a conseguir ler mais palavras e a descodificar mais grafemas do que as do grupo de controlo.

Assim, e tendo em conta que se trata de um estudo de natureza experimental, parece confirmar-se a existência de uma conexão causal entre a escrita e a leitura, mesmo ao nível do pré-escolar. Do ponto de vista qualitativo é de salientar a relativa sofisticação das estratégias das crianças do grupo experimental na leitura das palavras no momento dos pós-testes.

Por outro lado, o facto de ter havido generalização dos procedimentos de fonetização de letras trabalhadas para letras não trabalhadas, quer em situação de pós-teste, quer em situação de pós-teste postergado, vem reforçar a importância do impacto da escrita inventada nos procedimentos de leitura. Esses resultados contrariam os obtidos por Rieben et al. (2005), que não encontraram diferenças na leitura de palavras novas entre os grupos submetidos a programas de escrita inventada e o grupo de controlo. A inconsistência entre os resultados obtidos neste estudo e os resultados obtidos por Rieben et al. (2005) podem dever-se às características do Francês e do Português tendo, este último, uma ortografia mais transparente. Podem dever-se igualmente às características das palavras usadas na avaliação da leitura, que no caso do nosso estudo eram mais simples.

Os resultados obtidos no nosso estudo vão no mesmo sentido das hipóteses de Treiman (1998) e de Ouellette e Sénéchal, (2008b), que consideram que o acto de escrever, mesmo ao nível das escritas inventadas, favorece o desenvolvimento de competências de análise do oral que serão mobilizadas nas tentativas infantis de leitura. Segundo estes autores "a natureza exploratória das escritas inventadas encoraja as crianças a recorrer a uma abordagem analítica que promove a integração de informação fonológica e alfabética nas representações lexicais iniciais." (p. 26).

A importância da integração dessa informação para a aquisição da leitura é sustentada pela hipótese da qualidade lexical de Perfetti e Hart (2002), que consideram que a qualidade das representações internas lexicais é fundamental para o sucesso na leitura precoce de palavras.

Do ponto de vista educativo, o presente estudo proporciona fundamentação empírica para que os programas de intervenção sobre as escritas inventadas possam ser integrados nas práticas pedagógicas ao nível da educação infantil. A natureza das orientações dadas às crianças e o tipo e feedback parece-nos poder ser facilmente generalizável para um trabalho pedagógico em pequeno grupo. Aliás, consideramos importante que em futuras investigações este tipo de programas seja desenvolvido com pequenos grupos. Também as interacções que ocorrem entre as crianças e o experimentador devem ser objecto de análise em futuras investigações, de modo a perceber-se as razões que levam a que certas crianças evoluam mais do que outras.

Terminaremos apontando algumas limitações a este estudo. Em primeiro lugar, talvez tivesse sido interessante incluir no teste de leitura palavras com um leque mais alargado de consoantes não trabalhadas nas palavras do programa de intervenção, de forma a sustentar de forma mais rigorosa os efeitos de generalização do programa. Por outro lado, teria sido igualmente relevante avaliar se os benefícios em leitura se mantêm no decurso do processo de ensino formal da leitura. Teria sido também desejável controlar as práticas de literacia familiar, dado que podem ter influenciado os resultados obtidos.

\section{Referências}

Adams, M. (1998). Beginning to read: Thinking and learning about print. Cambridge, MA: MIT Press.

Alves Martins, M., \& Silva, C. (2006a). The impact of invented spelling on phonemic awareness. Learning and Instruction, 16, 41-5. doi: 10.1016/j.learninstruc.2005.12.005

Alves Martins, M., \& Silva, C. (2006b). Phonological abilities and writing among Portuguese preschool children. European Journal of Psychology of Education, 21, 163-182. doi: 10.1007/ BF0373575

Blanche-Beneviste, C. (2002). La escritura, irreducible a un "codigo". In E. Ferreiro (Ed.), Relaciones de (in)dependencia entre oralidad y escritura (pp. 15-30). Barcelona: Geddisa editorial.

Caravolas, M., Hulme, C., \& Snowling, M. J. (2001). The foundations of spelling ability: Evidence from 3-year longitudinal study. Journal of Memory and Language, 45, 751-754.

Cardoso-Martins, C., \& Batista, A. (2005). O conhecimento do nome das letras e o desenvolvimento da escrita: Evidência de crianças falantes do português. Psicologia: Reflexão e Crítica, 18, 330-336.

Chomsky, C. (1970). Reading, writing and phonology. Harvard Educational Review, 40, 287-309.

Clarke, L. K. (1988). Invented versus traditional spelling in first graders' writings: Effects on learning to spell and read. Research in the Teaching of English, 22, 281-309.

Clay, M. (1972). Reading: The patterning of complex behaviour. London: Heinemann.

Ehri, L. C. (1991). The development of reading and spelling in children: An overview. In M. Snowling \& M. Thomson (Eds.), Dyslexia: Integrating theory and practice (pp. 63-94). London: British Dyslexia Association.

Ehri, L. C., \& Wilce, L. S. (1987). Does learning to spell help beginners learn to read words? Reading Research Quarterly, 20, 47-65.

Ferreiro, E. (1988). L'écriture avant la lettre. In H. Sinclair (Ed.), La prodution des notations chez le jeune enfant (pp.18-69). Paris: Presses Universitaires de France.

Ferreiro, E., \& Teberosky, A. (1979). Los sistemas de escritura en el desarrollo del niño. México: Siglo XXI. 
Goswami, U., Ziegler, J. C., Dalton, L., \& Schneider, W. (2003). Nonword reading across orthographies: How flexible is the choice of reading units? Applied Psycholinguistics, 24, 235247. doi: 10.1017/S0142716403000134

Liberman, I. Y., Shankweiler, D., Fischer, F. W., \& Carter, B. (1974). Reading and the awareness of linguistic segments. Journal of Experimental Child Psychology, 18, 201-212. doi: 10.1016/0022-0965(74)90101-5

Mann, V. A. (1993). Phoneme awareness and future reading ability. Journal of Learning Disabilities, 26, 259-269.

McBride-Chang, C. (1998). The development of invented spelling. Early Education and Development, 9, 147-160. doi: 10.1207/ s15566935eed0902_3

Ouellette, G., \& Sénéchal, M. (2008a). A window into early literacy: Exploring the cognitive and linguistic underpinnings of invented spelling. Scientific Studies of Reading, 12(2), 195219. doi: 10.1080/10888430801917XXX

Ouellette, G., \& Sénéchal, M. (2008b). Pathways to literacy: A study of invented spelling and its role in learning to read. Child Development, 79(4), 899-913. doi: 10.1111/j.14678624.2008.01164.x

Perfetti, C. A., \& Hart, L. (2002). The lexical quality hypothesis. In L. Vehoeven. C. Elbro \& P. Reitsma (Eds.), Precursors of functional literacy (pp. 189-213). Amsterdam/Philadelphia: John Benjamins.

Raven, J., Raven, J. C., \& Court, J. H. (1998). Manual for Raven's Progressive Matrices and Vocabulary Scale. Section I. General Overview. Oxford: Oxford Psychologists Press.
Read, C. (1971). Pre-school children's knowledge of English phonology. Harvard Educational Review, 41, 1-34.

Rieben, L., Ntamakiliro, L., Gonthier, B., \& Fayol, M. (2005). Effects of various early writing practices on reading and spelling. Scientific Studies of Reading, 9, 145-166. doi: 10.1207/s1532799xssr0902_3

Richgels, D. (1995). Invented spelling ability and printed word learning in kindergarten. Reading Research Quarterly, 30(1), 96-109.

Shatil, E., Share, D. L., \& Levin, I. (2000). On the contribution of kindergarten writing to grade 1 literacy: a longitudinal study in Hebrew. Applied Psycholinguistics, 21, 1-21.

Silva, C. (2008). Bateria de provas fonológicas. Lisboa: ISPA.

Silva, C., \& Alves Martins, M. (2002). Phonological skills and writing of pre-syllabic children. Reading Research Quarterly, 37, 466-483. doi: 10.1598/RRQ.37.4.6

Tolchinsky, L. (2005). The emergence of writing. In C. MacArthur, S. Graham \& J. Fitzgerald (Eds.), Handbook of writing research (pp. 83-96). New York: Guilford.

Treiman, R. (1998). Why spelling? The benefits of incorporating spelling into beginning reading instruction. In J. L. Metsala \& L.C. Ehri (Eds.), Word recognition in beginning literacy (pp. 289-313). Mahwah, NJ: Erlbaum.

Treiman, R. (2004). Phonology and spelling. In P. Bryant \& T. Nunes (Eds.), Handbook of children's literacy (pp. 31-42). Dordrecht, the Netherlands: Kluwer.

Recebido em 25.11.2012

Primeira decisão editorial em 07.05.2014

Versão final em 23.05.2014

Aceito em 02.12.2014 